\title{
Expression of GP88 (progranulin) in serum of prostate cancer patients is associated with Gleason scores and overall survival
}

This article was published in the following Dove Press journal: Cancer Management and Research

\author{
Thomas Greither, ${ }^{1, *}$ \\ Kersten Fischer, ${ }^{2, *}$ Gerit \\ Theil, ${ }^{2}$ Marios Marcou, ${ }^{1,2}$ \\ Hans-Juergen Holzhausen, ${ }^{3}$ \\ Katrin Weigelt, ${ }^{4}$ Ginette \\ Serrero, ${ }^{5,6}$ David Hicks, ${ }^{5}$ \\ Binbin Yue, ${ }^{5}$ Paolo Fornara, ${ }^{2}$ \\ Bernd Wullich, ${ }^{4}$ Helge \\ Taubert, ${ }^{4}$ Sven Wach, ${ }^{4}$ \\ Verena Lieb ${ }^{4}$ \\ 'Center for Reproductive Medicine \\ and Andrology, Martin Luther \\ University Halle-Wittenberg, \\ Halle, Germany; ${ }^{2}$ Department of \\ Urology, Martin Luther University \\ Halle-Wittenberg, Halle, Germany; \\ ${ }^{3}$ Department of Pathology, Martin \\ Luther University Halle-Wittenberg, \\ Halle, Germany; ${ }^{4}$ Department of \\ Urology and Pediatric Urology, \\ Universitätsklinikum Erlangen, \\ Friedrich-Alexander-Universität \\ Erlangen-Nürnberg, Erlangen, \\ Germany; ${ }^{5} A \& G$ Pharmaceutical Inc., \\ Columbia, Maryland, USA; ${ }^{\circ}$ Program \\ in Oncology, University of Maryland \\ Greenebaum Comprehensive Cancer \\ Center, Baltimore, Maryland, USA \\ *These authors contributed equally to \\ this work
}

Correspondence: Helge Taubert Division of Molecular Urology, Department of Urology, University Hospital Erlangen, Hartmannstr. I4, 91052 Erlangen, Germany

Tel +49 9 I 3 | 8523373

Fax +49 9 । 3 | 8523374

Email helge.taubert@uk-erlangen.de
Background: GP88/Progranulin is a well-recognized cell growth promoter in different cancers, and elevated serum GP88 levels have been described as negative prognostic factor in breast cancer. However, serum levels in prostate cancer $(\mathrm{PCa})$ patients have not yet been studied.

Material and Methods: We analyzed serum GP88 levels by enzyme immunosorbent assay and correlated them with clinicopathological parameters in PCa patients. PCa patients were separated into two groups based on the serum GP88 median level (low $\leq 44.56 \mathrm{ng} / \mathrm{mL}$ or high $>44.56 \mathrm{ng} / \mathrm{mL}$ ) and according to their median age (younger $\leq 66$ years or elder patients $>66$ years). Results: Low serum GP88 levels were more often detected in younger patients and high levels in elder patients ( $P=0.018$; Fisher's exact test). PCa patients were separated into three groups, Gleason score $(\mathrm{GS}) \leq 6 ; \mathrm{GS}=7$; and $\mathrm{GS} \geq 8$. In receiver operating characteristic analyses, we could distinguish $\mathrm{GS} \leq 6$ from $\mathrm{GS}=7$ [area under the curve (AUC): 0.646; $P=0.018$ ] and $\mathrm{GS} \leq 6$ from $\mathrm{GS} \geq 8$ (AUC: $0.629 ; P=0.048$ ) but not $\mathrm{GS}=7$ from $\mathrm{GS} \geq 8$. For survival analysis, GP88 levels were separated into two groups by an optimized cutoff value of $36.92 \mathrm{ng} / \mathrm{mL}$. Using this GP88 stratification, all PCa patients and younger patients with a low serum GP88 level had a significantly better overall survival compared with patients with higher serum GP88 levels (log-rank test $P=0.010$ and $P=0.024$ ). Conclusion: Serum GP88 levels are significantly different depending on age and GS, and they are associated with the prognosis of $\mathrm{PCa}$ patients.

Keywords: GP88, progranulin, prostate cancer, Gleason score

\section{Introduction}

GP88/Progranulin (GRN/PGRN), also known as teratoma PC cell-derived growth factor/PCDGF, acrogranin, granulin/epithelin precursor, is an $88-\mathrm{kD}$ glycoprotein reported as an autocrine proliferation and survival factor for several cancer types. ${ }^{1}$ The $P G R N$ gene was first cloned from human bone marrow and revealed 71/2 tandem double cysteine-rich granulin domains. ${ }^{2}$ GP88/PGRN stimulates proliferation in mesenchymal and epithelial cells via activation of different kinase pathways, such as mitogen-activated protein kinase (Erk1/2), phosphatidylinositol 3'-kinase, and focal adhesion kinase pathways. ${ }^{3,4}$ Its overexpression is associated with several drug resistance mechanisms in breast cancer cells, ie, it confers trastuzumab resistance to Her2overexpressing cells, letrozole resistance to aromatase overexpressing cells, tamoxifen resistance in MCF7 cells, doxorubicin resistance in MCF7 cells, and also resistance to dexamethasone in human multiple myeloma. ${ }^{4-9}$ Elevated serum GP88 levels have been reported in patients with rheumatoid arthritis, breast cancer, lung cancer, malignant lymphoma, and ovarian cancer. ${ }^{10-14} \mathrm{~A}$ recently published study carried out with a cohort of Korean patients indicated that serum GP88 levels were clinically significant 
for predicting recurrence in patients with hormone receptorpositive breast cancer during adjuvant tamoxifen therapy. ${ }^{15}$

Concerning prostate cancer $(\mathrm{PCa})$, published in vitro biological studies have reported that GP88/PGRN promotes cell growth, migration, and anchorage-independent growth. ${ }^{16}$ In addition, pathological studies on GP88 expression have indicated that while GP88 expression is negative in normal prostate epithelium prostatic intraepithelial neoplasia (PIN) lesions, GP88 expression was significantly increased in PCa lesions. ${ }^{17}$ However, serum GP88 levels have not been investigated in PCa patients. The present study investigated whether there were differences in the level of circulating GP88/PGRN levels using a GP88-specific enzyme immunosorbent assay (EIA).

\section{Patients and methods}

\section{Patients}

One hundred forty-two prostate carcinoma patients were recruited to this study, which was positively evaluated by the local ethics committee of the Medical Faculty of the Martin Luther University and is in accordance with the precepts established by the Declaration of Helsinki. All patients gave written informed consent. Twenty-five patients developed distant metastases and two patients already had metastases when the blood sampling was performed. The patients are part of the cohort that has been previously described ${ }^{18}$ (Tables 1 and S1).

Table I Clinicopathological data and GP88 levels

\begin{tabular}{|c|c|c|c|c|c|}
\hline & \multirow{2}{*}{$\frac{\mathbf{P C a}}{\mathrm{All}}$} & \multirow{2}{*}{$\frac{\text { PCa }}{\text { Younger patients }}$} & \multirow{2}{*}{$\frac{\text { PCa }}{\text { Elder patients }}$} & \multicolumn{2}{|l|}{ GP88 levels } \\
\hline & & & & $\leq 36.92 \mathrm{ng} / \mathrm{mL}$ & $>36.92 \mathrm{ng} / \mathrm{mL}$ \\
\hline $\mathrm{N}$ & 142 & 71 & 7I & 42 & 100 \\
\hline \multicolumn{6}{|l|}{ Age } \\
\hline Range & $44-91$ & $44-66$ & 67-91 & & \\
\hline Mean & 65.8 & 59.94 & 71.81 & & \\
\hline Median & $66.5^{\mathrm{a}}$ & 61.00 & 70.00 & & \\
\hline$\leq 66$ years & 71 & 71 & n.a. & 24 & 47 \\
\hline$>66$ years & 71 & n.a. & 7I & 18 & 53 \\
\hline \multicolumn{6}{|l|}{ Gleason sum } \\
\hline$\leq 6$ & 39 & 22 & 17 & 18 & 21 \\
\hline 7 & 52 & 30 & 22 & II & 41 \\
\hline$\geq 8$ & 41 & 15 & 26 & 10 & 31 \\
\hline Unknown & 10 & 4 & 6 & 3 & 7 \\
\hline \multicolumn{6}{|l|}{ Tumor stage } \\
\hline $\mathrm{TI} / 2$ & 95 & 51 & 44 & 26 & 69 \\
\hline $\mathrm{T} 3 / 4$ & 44 & 20 & 24 & 16 & 28 \\
\hline Unknown & 3 & 0 & 3 & 0 & 3 \\
\hline \multicolumn{6}{|c|}{ Distant metastases } \\
\hline Mo & 31 & 18 & 13 & 9 & 22 \\
\hline$M I$ & 25 & II & 14 & 3 & 22 \\
\hline$M X$ & 86 & 42 & 44 & 30 & 56 \\
\hline \multicolumn{6}{|l|}{ PSA } \\
\hline$<4 \mathrm{ng}$ & 45 & 22 & 23 & 12 & 33 \\
\hline$\geq 4 \mathrm{ng}$ & 97 & 49 & 48 & 30 & 67 \\
\hline Range $^{b}$ & $0-1,625$ & $0-1,625$ & $0-503$ & $0-209$ & $0-1,625$ \\
\hline Mean & 51.1 & 71.4 & 30.9 & 17.2 & 65.4 \\
\hline Median & 6.2 & 5.6 & 7.8 & 6.0 & 6.4 \\
\hline \multicolumn{6}{|c|}{ Overall survival } \\
\hline Alive & 112 & 61 & 51 & 37 & 80 \\
\hline Dead & 30 & 10 & 20 & 5 & 20 \\
\hline \multicolumn{6}{|c|}{ Disease-specific survival } \\
\hline Alive & 132 & 68 & 64 & 39 & 93 \\
\hline Dead & 10 & 3 & 7 & 3 & 7 \\
\hline \multicolumn{6}{|c|}{ GP88 levels (ng/mL) } \\
\hline Range & $0-208.48$ & $19.6 \mid-147.04$ & $0-208.48$ & n.a. & n.a. \\
\hline Mean & 48.67 & 46.03 & 51.31 & n.a. & n.a. \\
\hline Median & 44.56 & 40.60 & 47.58 & n.a. & n.a. \\
\hline
\end{tabular}

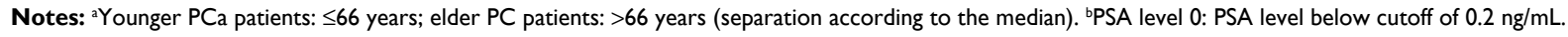
Abbreviations: n.a., not applicable; PCa, prostate cancer; PSA, prostate specific antigen. 


\section{Preanalytical sampling}

Ten microliters of venous blood was obtained during patient follow-up and immediately processed by centrifugation at $400 \times g$. Serum was transferred in a separate reaction tube and stored at $-80^{\circ} \mathrm{C}$. For about $70 \%$ of the patients, blood sampling occurred before surgery or treatment. Further, blood sampling details are given in Table S2. Serum GP88 level was not different between the blood sampling groups (Kruskal-Wallis test: $P=0.181$; data not shown).

\section{GP88 EIA}

Serum GP88 levels were determined by a quantitative GP 88 sandwich EIA developed and manufactured by A\&G Pharmaceutical Inc., Columbia, MD, USA, as described previously, ${ }^{10}$ using the antihuman GP88 6B3 monoclonal antibody as coating antibody $(10 \mu \mathrm{g} / \mathrm{mL})$ and rabbit polyclonal $37 \mathrm{k}$ antibody as detection antibody. Standard samples (consisting of human GP88 at concentrations from 0 to $20 \mathrm{ng} / \mathrm{mL}$ ) were measured in duplicates and patients and control samples in triplicates. EIA reaction was measured by absorbance readout at 620 $\mathrm{nm}$ on a GENios Microplate Reader (Tecan, Männedorf, Switzerland), and serum GP88 levels were quantified against the human GP88 standard curve.

\section{Statistics}

Statistics were performed with SPSS 20.0 (IBM, Ehningen, Germany). Distribution of serum GP88 levels between different groups [Gleason score (GS)] was compared with nonparametric tests (Mann-Whitney U-test; Kruskal-Wallis test). Serum GP88 concentrations and patients' age were divided according to the median and groups were compared by chi-squared tests (Fisher's exact test). Diagnostic applicability was analyzed by receiver operating characteristics (ROCs). Survival analyses were performed with Kaplan-Meier analyses and univariate/multivariate Cox's regression analyses. Overall survival (OS) was considered from the date of serum collection (that was applied for the analysis of GP88 levels) to the last contact (death or last follow-up date).

\section{Results}

\section{Expression of GP88 in serum of PCa patients}

Serum of $142 \mathrm{PCa}$ was analyzed for GP88 levels by EIA. The PCa patients showed a mean level of $48.67 \mathrm{ng} / \mathrm{mL}$ (median: $44.56 \mathrm{ng} / \mathrm{mL}$; range $0-208.48 \mathrm{ng} / \mathrm{mL}$ ).

\section{Correlation of GP88 levels with clinicopathological parameters}

Serum GP88 level was not different in PSA level groups ( $<4 \mathrm{ng}$ vs $\geq 4 \mathrm{ng}$ ) or tumor stage groups (T1/2 vs T3/4) but was different with borderline significance in age groups ( $\leq 66$ years vs $>66$ years; $P=0.068$ ) in nonparametric tests.

Next, PCa patients were separated by their median of serum GP88 level in two groups (low: $\leq 44.56 \mathrm{ng} / \mathrm{mL}$ vs high levels: $>44.56 \mathrm{ng} / \mathrm{mL}$ ). Low serum GP88 levels were more often detected in younger patients ( $\leq 66$ years) and high levels in elder patients ( $>66$ years; $P=0.018$; Fisher's exact test).

The Gleason scores (GS) of the PCa patients were separated into three groups; GS $\leq 6, \mathrm{GS}=7$, and $\mathrm{GS} \geq 8$. In $\mathrm{PCa}$ patients with GS $\leq 6$, serum GP88 levels were lower (mean $41.8 \mathrm{ng} / \mathrm{mL}$; median: $40.5 \mathrm{ng} / \mathrm{mL}$ ) than in patients with $\mathrm{GS}=7$ (mean: $52.2 \mathrm{ng} / \mathrm{mL}$; median $46.6 \mathrm{ng} / \mathrm{mL}$ ). The serum GP88 levels for patients with $\mathrm{GS}=7$ were comparable with levels observed in $\mathrm{GS} \geq 8$ patients (mean: $51.5 \mathrm{ng} / \mathrm{mL}$; median: 45.2 $\mathrm{ng} / \mathrm{mL})$. The GP88 levels appeared as not equally distributed between the three GS groups ( $P=0.043$; Kruskal-Wallis test). Interestingly, in ROC analyses using serum GP88 levels, it was possible to distinguish $\mathrm{GS} \leq 6$ from $\mathrm{GS}=7$ [area under the curve (AUC): $0.646 ; P=0.018$; Figure 1] and $\mathrm{GS} \leq 6$ from $\mathrm{GS} \geq 8$ (AUC: $0.629 ; P=0.048$; Figure 1) but not $\mathrm{GS}=7$ from $\mathrm{GS} \geq 8$.

\section{Association of GP88 levels with OS in PCa patients}

An optimal serum GP88 cutoff level of $36.92 \mathrm{ng} / \mathrm{mL}$ was determined by ROC analysis for all PCa patients and the younger PCa patients. Kaplan-Meier analysis revealed that for all PCa patients the group with a lower GP88 levels $(\leq 36.92 \mathrm{ng} / \mathrm{mL})$ had a significantly longer OS of 111.9 months (95\% CI: 102.8-121.2 months) than the group with higher levels $(>36.92 \mathrm{ng} / \mathrm{mL})$ with an OS of 88.8 months (95\% CI: 77.6-100.1 months; $P=0.010$; log-rank test, Kaplan-Meier analysis; Table 2). Univariate Cox's regression analysis showed that the group with higher GP88 levels possessed a 3.3-fold increased risk of death $(P=0.015)$ compared with the low-level GP88 group (Table 2). In a multivariate Cox's regression backward analysis (adjusted for Gleason grade and tumor stage), the tumor stage [relative risk $(\mathrm{RR})=$ 2.7; $P=0.018]$ and GP88 level $(\mathrm{RR}=3.0 ; P=0.032)$ remained as independent prognostic factors (Table 2 ).

After separating the PCa patients into two groups according to the median age, the younger patients with a low serum GP88 level $(\leq 36.92 \mathrm{ng} / \mathrm{mL})$ had a significantly better prognosis with a mean OS of 119.9 months $(95 \%$ 


\section{A}
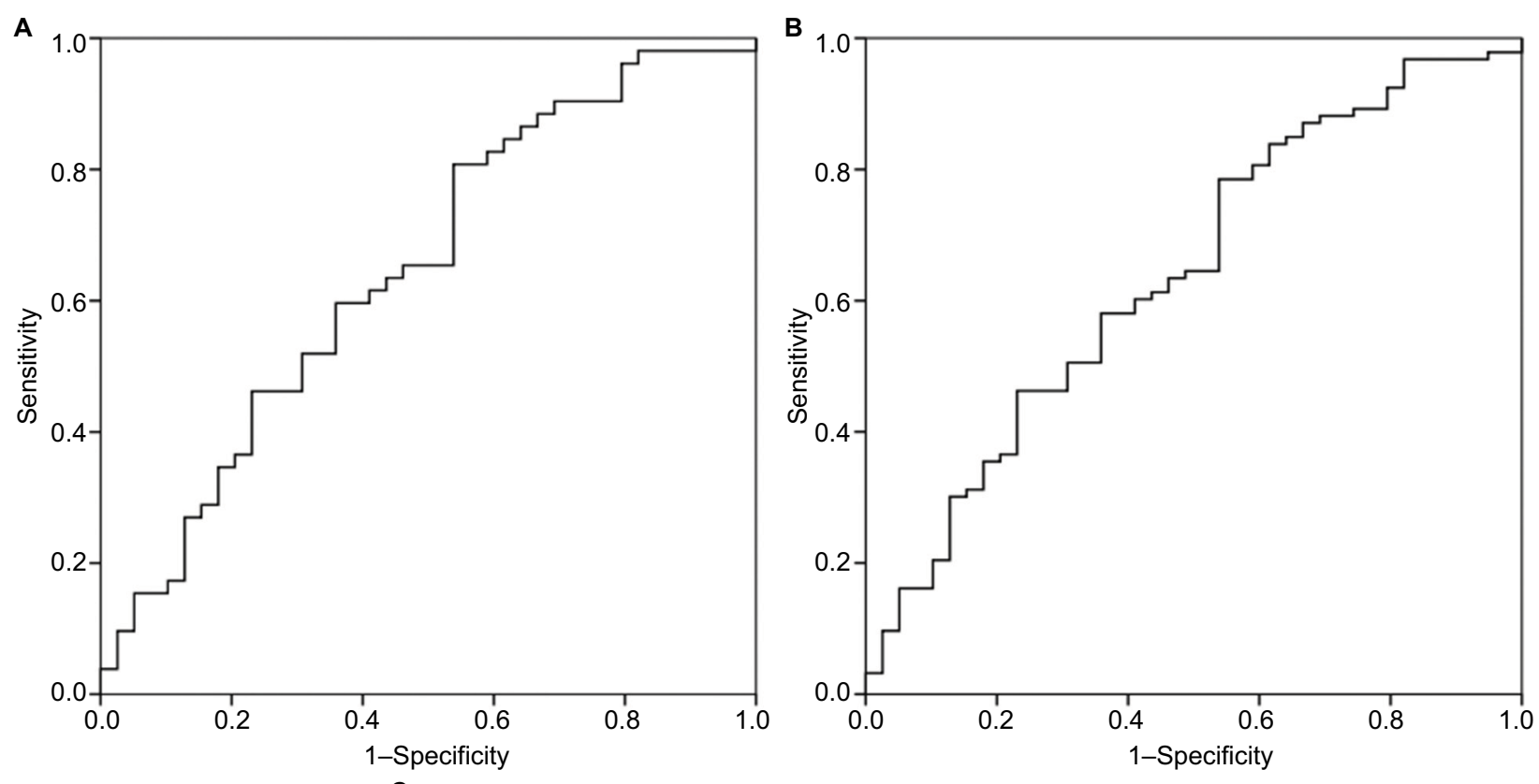

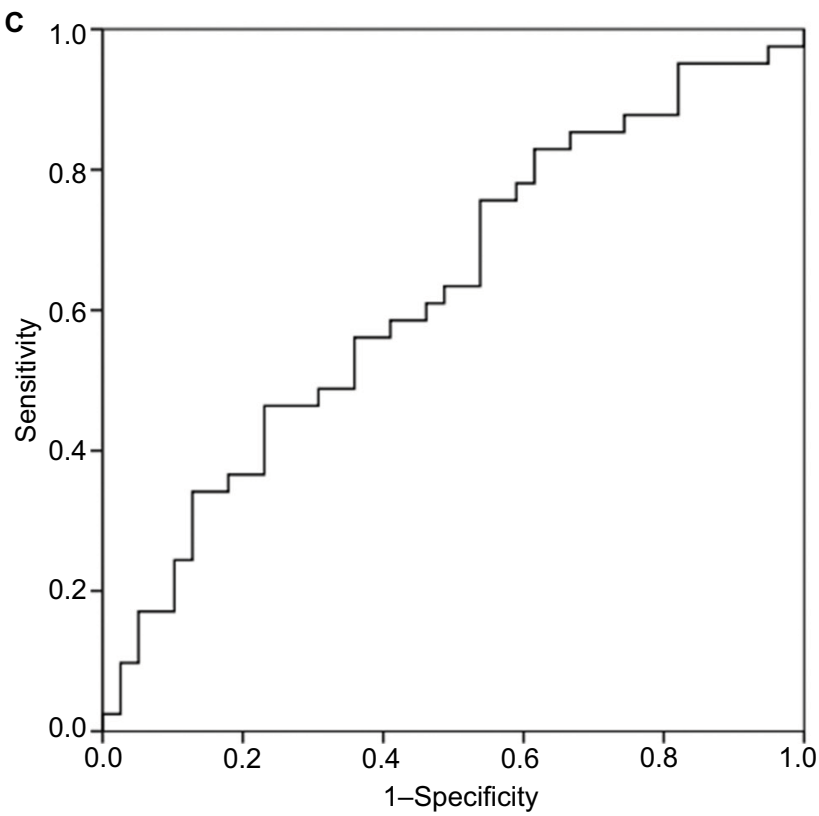

Figure I ROC analyses: separation of GSs by serum GP88 levels.

Notes: (A) Separation of GS $\leq 6$ from GS=7 by ROC analysis shows an area under the curve (AUC) of 0.646 ( $P=0.018$ ), (B) separation of GS $\leq 6$ from GS $\geq 8$ shows an $A \cup C$ of 0.629 ( $P=0.048)$, and $(C)$ separation of $G S \leq 6$ from $G S>6$ shows an $A \cup C$ of $0.638(P=0.012)$.

Abbreviations: GS, Gleason score; PCa, prostate cancer; ROC, receiver operating characteristics.

CI: 114.1-125.7 months) compared with the younger patients with higher GP88 levels $(>36.92 \mathrm{ng} / \mathrm{mL})$ who had a mean OS of 100.7 months (95\% CI: 86.0-115.5 months; $P=0.024$; log-rank test; Kaplan-Meier analysis; Figure 2; Table 2).

Univariate Cox's regression analysis revealed that higher GP88 level in younger patients was associated with a 7.75fold increased risk of death, although only with a border line significance $(P=0.054)$ probably due to the limited number of patients in the study (Table 2). However, there was no association between serum GP88 levels and OS in elder patients ( $P=0.337$, log-rank test; Table 2 ) and no association between GP88 levels and tumor-specific survival for all patients or all age patient groups (data not shown).

\section{Discussion}

GP88/PGRN has been shown to be a critical driver of tumorigenesis in several cancer types. ${ }^{19}$ In particular, biological 
Table 2 Association of serum GP88 levels with overall survival

\begin{tabular}{|c|c|c|c|c|c|c|}
\hline & \multicolumn{2}{|c|}{ Kaplan-Meier analysis } & \multicolumn{2}{|c|}{$\begin{array}{l}\text { Univariate Cox's } \\
\text { regression analysis }\end{array}$} & \multicolumn{2}{|c|}{$\begin{array}{l}\text { Multivariate Cox's } \\
\text { regression analysis }\end{array}$} \\
\hline & Months & $P$ & $\overline{\mathbf{R R}}$ & $P$ & $\overline{\mathbf{R R}}$ & $P$ \\
\hline \multicolumn{7}{|l|}{ All PCa patients } \\
\hline GP88 $\leq 36.92 \mathrm{ng} / \mathrm{mL}$ vs $>36.92 \mathrm{ng} / \mathrm{mL}$ & 111.9 vs 88.8 & 0.010 & 3.3 & 0.015 & 3.0 & 0.032 \\
\hline \multicolumn{7}{|l|}{ Younger PCa patients ( $\leq 66$ years) } \\
\hline GP88 $\leq 36.92 \mathrm{ng} / \mathrm{mL}$ vs $>36.92 \mathrm{ng} / \mathrm{mL}$ & II9.9 vs 100.7 & 0.024 & 7.7 & 0.054 & 7.5 & 0.076 \\
\hline \multicolumn{7}{|l|}{ Elder PCa patients ( $>66$ years) } \\
\hline GP88 $\leq 36.92 \mathrm{ng} / \mathrm{mL}$ vs $>36.92 \mathrm{ng} / \mathrm{mL}$ & 94.7 vs 72.0 & 0.337 & 1.7 & 0.343 & 1.8 & 0.343 \\
\hline
\end{tabular}

Note: Significant values are given in bold face.

Abbreviations: PCa, prostate cancer; RR, relative risk.

studies have established that GP88 plays a major role in stimulating survival, angiogenesis, drug resistance, migration, and invasion, all hallmarks of tumor aggressiveness and poor prognosis. ${ }^{20,21}$ Pathological studies have also shown that for several types of cancer, GP88 was overexpressed in tumor biopsies, whereas it was not expressed in normal tissues and/ or benign lesions. ${ }^{22}$ Additionally, elevated serum or plasma levels have been reported in breast, lung, lymphomas, and ovarian cancers. ${ }^{10,11,13,14}$ Both biological and pathological studies have underscored the role of GP88 expression in PCa. ${ }^{16,17,19}$ However, up to now, no investigation of GP88 levels in serum of PCa patients had been undertaken. In the present study, we examined serum GP88 levels in PCa patients. The detected mean GP88 levels $(48.67 \mathrm{ng} / \mathrm{mL})$ were comparable with the levels detected in patients with breast cancer $(45.3 \mathrm{ng} / \mathrm{mL})$, lung cancer $(49.9 \mathrm{ng} / \mathrm{mL})$, rheumatoid arthritis $(50.2 \mathrm{ng} / \mathrm{mL})$, and osteoarthritis $(45.4 \mathrm{ng} / \mathrm{mL})$ but slightly increased compared with published serum GP88 levels in healthy subjects $(28.7 \pm 5.8 \mathrm{ng} / \mathrm{mL}) .{ }^{11,12,14}$ Interestingly, we detected for the first time that serum GP88 levels were age associated, ie, increased in elder PCa patients. However, previous studies have not shown an age association with serum GP88 levels in healthy male volunteers $(\mathrm{N}=260$; mean age 50 years $)$ or in breast cancer patients $(\mathrm{N}=189$, median age 51 years). ${ }^{11,12}$ GP88 levels in GS=7 and GS $\geq 8$ $\mathrm{PCa}$ patients were significantly increased compared with $\mathrm{GS} \leq 6 \mathrm{PCa}$ patients. This finding would suggest that serum GP88 determination could provide complementary information to the GS evaluation. However, other diseases such as rheumatoid arthritis and osteoarthritis, found preferentially in an older population, also show elevated serum GP88 levels. Therefore, further studies are required to evaluate the relationship between age/GS and GP88 levels in PCa patients, particularly in older populations where these diseases maybe more prevalent.
When applying an optimized GP88 cutoff level of $36.92 \mathrm{ng} /$ $\mathrm{mL}$ based on ROC analysis, it was found that $\mathrm{PCa}$ patients could be stratified into two groups with better or worse OS. We could show for the first time that a low GP88 level was significantly associated with better OS in PCa patients. PCa patients with high(er) GP88 levels had a significantly increased risk of death $(\mathrm{RR}=3.0)$. Multivariate Cox's regression analysis showed that serum GP88 level was an independent prognostic factor for OS in PCa patients. It is interesting to note that in younger patients (N=71), low GP88 levels were significantly associated with a better prognosis when compared with patients with higher serum GP88. In fact, the low levels of GP88 in the younger PCa patients (19.61-36.92 ng/mL; Table 1) were rather comparable with those reported in healthy subjects $(28.7 \pm 5.8 \mathrm{ng} / \mathrm{mL})$. But the high levels of GP88 in the younger patients (>36.92-147.04 $\mathrm{ng} / \mathrm{mL}$ ) associated with shorter OS were in almost all cases above the levels previously reported in healthy subjects. ${ }^{11,14} \mathrm{It}$ is surprising to note that there was no association between the GP88 levels and OS in the elder patient group. However, it is conceivable that this could be due to the fact that the OS of the older population is expectedly shorter than that of the younger population. It is also possible that GP88 levels may play different roles in prostate biology in younger and older patients.

Furthermore, in addition to its role as prognostic factor, GP88 shows potential as therapeutic target. In particular, inhibition of GP88 in urothelial cancer cells resulted in the inhibition of cell migration, invasion, and anchorage-independent growth in vitro, and it resensitized urothelial cancer cells to cisplatin. Moreover, urothelial cells stably transfected with GP88/PGRN shRNA displayed a reduction of tumor growth in xenograft and orthotopic mouse tumor models. ${ }^{23}$

Altogether, the analysis of GP88 levels in a liquid biopsy, ie, the serum of PCa patients, may provide additional information to better assess tumor differentiation and prognosis especially in younger PCa patients in a noninvasive way. 

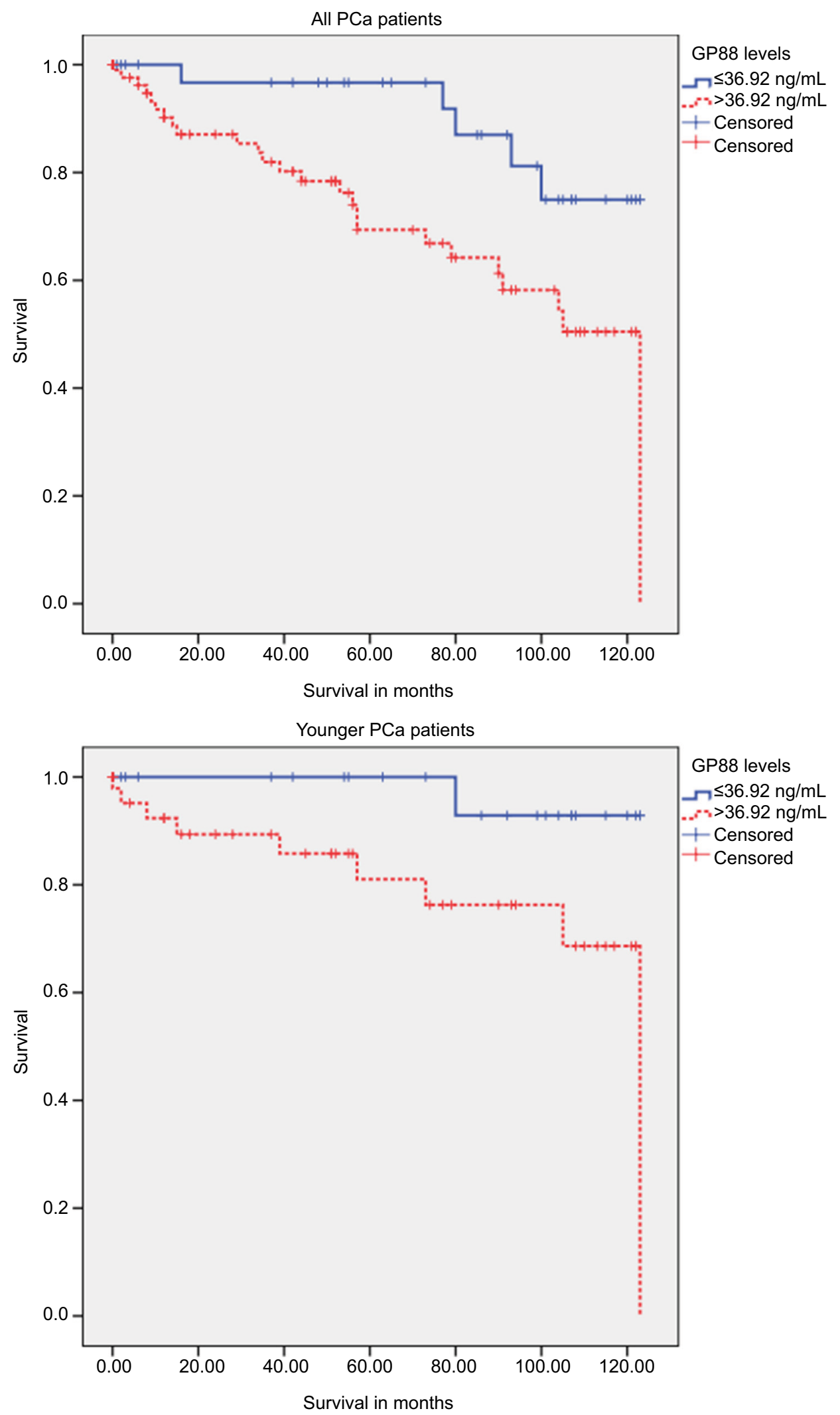

Figure 2 Kaplan-Meier analyses.

Notes: Association of OS with GP88 levels in applying an optimized cutoff. A longer OS was significantly associated with a low GP88 level ( $\leq 36.92$ ng/mL) in all PCa patients $(P=0.010)$ and in the younger $P C a$ patient group $(P=0.024)$ but not in the elder patient group.

Abbreviations: $\mathrm{PCa}$, prostate cancer; OS, overall survival. 


\section{Acknowledgments}

The authors thank the Rudolf und Irmgard KleinknechtStiftung for supporting HT, the Johannes und Frieda MarohnStiftung for supporting HT and SW, and the ELAN Fonds for supporting VL (14-07-11-1-Huppert). They are thankful to Dr P Schmidt/Tumorzentrum Martin Luther University Halle-Wittenberg for his help with follow-up data. They also acknowledge the financial support of the Open Access Publication Fund of the Martin-Luther-University Halle-Wittenberg.

\section{Disclosure}

GS, DH, and BY are employees of A\&G Pharmaceutical Inc., Columbia, Maryland, USA. The authors report no other conflicts of interest in this work.

\section{References}

1. Zhang H, Pan CX, Cheng L. GRN (granulin). Atlas Genet Cytogenet Oncol Haematol. 2008;12:208-212.

2. Bhandari V, Palfree RG, Bateman A. Isolation and sequence of the granulin precursor cDNA from human bone marrow reveals tandem cysteine-rich granulin domains. Proc Natl Acad Sci U S A. 1992;89(5):1715-1719.

3. Bateman A, Bennett HP. The granulin gene family: from cancer to dementia. Bioessays. 2009;31(11):1245-1254.

4. Serrero G. Autocrine growth factor revisited: PC-cell-derived growth factor (progranulin), a critical player in breast cancer tumorigenesis. Biochem Biophys Res Commun. 2003;308(3):409-413.

5. Tangkeangsirisin W, Hayashi J, Serrero G. PC cell-derived growth factor mediates tamoxifen resistance and promotes tumor growth of human breast cancer cells. Cancer Res. 2004;64(5):1737-1743.

6. Kim WE, Serrero G. PC cell-derived growth factor stimulates proliferation and confers Trastuzumab resistance to Her-2-overexpressing breast cancer cells. Clin Cancer Res. 2006;12(14 Pt 1):4192-4199.

7. Wang W, Hayashi J, Serrero G. PC cell-derived growth factor confers resistance to dexamethasone and promotes tumorigenesis in human multiple myeloma. Clin Cancer Res. 2006;12(1):49-56.

8. Abrhale T, Brodie A, Sabnis G, et al. GP88 (PC-Cell Derived Growth Factor, progranulin) stimulates proliferation and confers letrozole resistance to aromatase overexpressing breast cancer cells. BMC Cancer. $2011 ; 11: 231$
9. Kudoh K, Ramanna M, Ravatn R, et al. Monitoring the expression profiles of doxorubicin-induced and doxorubicin-resistant cancer cells by cDNA microarray. Cancer Res. 2000;60(15):4161-4166.

10. Han JJ, Yu M, Houston N, Steinberg SM, Kohn EC. Progranulin is a potential prognostic biomarker in advanced epithelial ovarian cancers. Gynecol Oncol. 2011;120(1):5-10.

11. Tkaczuk KR, Yue B, Zhan M, et al. Increased circulating level of the survival factor GP88 (Progranulin) in the serum of breast cancer patients when compared to healthy subjects. Breast Cancer. 2011;5:155-162.

12. Yamamoto Y, Takemura M, Serrero G, et al. Increased serum GP88 (Progranulin) concentrations in rheumatoid arthritis. Inflammation. 2014;37(5):1806-1813.

13. Yamamoto Y, Goto N, Takemura M, et al. Association between increased serum GP88 (progranulin) concentrations and prognosis in patients with malignant lymphomas. Clin Chim Acta. 2017;473:139-146.

14. Edelman MJ, Feliciano J, Yue B, et al. GP88 (progranulin): a novel tissue and circulating biomarker for non-small cell lung carcinoma. Hum Pathol. 2014;45(9):1893-1899.

15. Koo DH, Park CY, Lee ES, Ro J, Oh SW. Progranulin as a prognostic biomarker for breast cancer recurrence in patients who had hormone receptor-positive tumors: a cohort study. PLoS One. 2012;7(6):e39880.

16. Monami G, Emiliozzi V, Bitto A, et al. Proepithelin regulates prostate cancer cell biology by promoting cell growth, migration, and anchorageindependent growth. Am J Pathol. 2009;174(3):1037-1047.

17. Pan CX, Kinch MS, Kiener PA, et al. PC cell-derived growth factor expression in prostatic intraepithelial neoplasia and prostatic adenocarcinoma. Clin Cancer Res. 2004;10(4):1333-1337.

18. Wach S, Al-Janabi O, Weigelt K, et al. The combined serum levels of miR-375 and urokinase plasminogen activator receptor are suggested as diagnostic and prognostic biomarkers in prostate cancer. Int J Cancer. 2015;137(6):1406-1416.

19. Tanimoto R, Lu KG, Xu S-Q, et al. Mechanisms of progranulin action and regulation in genitourinary cancers. Front Endocrinol. 2016;7: $1-7$.

20. Abella V, Pino J, Scotece M, et al. Progranulin as a biomarker and potential therapeutic agent. Drug Discov Today. 2017;22(10):1557-1564.

21. Arechavaleta-Velasco F, Perez-Juarez CE, Gerton GL, Diaz-Cueto L. Progranulin and its biological effects in cancer. Med Oncol. 2017;34(12):194.

22. Serrero G. Potential of theranostic target mining in the development of novel diagnostic and therapeutic products in oncology: progranulin/ GP88 as a therapeutic and diagnostic target for breast and lung cancers. Rinsho Byori. 2016;64:1296-1309.

23. Buraschi S, Xu SQ, Stefanello M, et al. Suppression of progranulin expression inhibits bladder cancer growth and sensitizes cancer cells to cisplatin. Oncotarget. 2016;7(26):39980-39995. 


\section{Supplementary materials}

Table SI Treatment options

\begin{tabular}{ll}
\hline Treatment options & N \\
\hline Radical prostatectomy & 59 \\
Radiation & 26 \\
Chemotherapy & 15 \\
TUR-P & $\mathrm{II}$ \\
TUR-P+HIFU & $\mathrm{I}$ \\
HIFU & 2 \\
Adenomectomy & $\mathrm{I}$ \\
Orchiectomy & $\mathrm{I}$ \\
Varicocele surgery & $\mathrm{I}$ \\
Lymphadenectomy & $\mathrm{I}$ \\
No treatment & 34
\end{tabular}

Abbreviations: TUR-P, transurethral resection of the prostate; HIFU, highintensity focused ultrasound.
Table S2 Blood sampling

\begin{tabular}{ll}
\hline Blood sampling & $\mathbf{N}$ \\
\hline Before operation and no pretreatment & 58 \\
Before operation and pretreatment & 5 \\
No operation and no pretreatment & 36 \\
After operation and no treatment & 16 \\
After operation and further treatment & 27 \\
All & 142 \\
\hline
\end{tabular}

Cancer Management and Research

\section{Publish your work in this journal}

Cancer Management and Research is an international, peer-reviewed open access journal focusing on cancer research and the optimal use of preventative and integrated treatment interventions to achieve improved outcomes, enhanced survival and quality of life for the cancer patient. The manuscript management system is completely online and includes

Submit your manuscript here: https://www.dovepress.com/cancer-management-and-research-journal

a very quick and fair peer-review system, which is all easy to use. Visit http://www.dovepress.com/testimonials.php to read real quotes from published authors. 